thromboembolic occlusive vascular disease, for which in any event side-effects render it unsafe. On the other hand, as the present studies demonstrate, Complamin clearly does not exploit the full fibrinolytic potential of the body, and a search for further modifications of nicotinic acid or other pharmacological substances which would produce a sustained fibrinolytic response would seem worth while. In particular, a non-toxic substance administered by mouth might, by long-term administration to increase physiological fibrinolytic activity, have an important role in the prophylaxis of vascular thrombosis.

\section{Summary}

Complamin, a nicotinic-acid/theophylline ester, produces brisk but transient fibrinolytic activity when injected or infused intravenously. A refractory state soon appears, in which patients do not respond to further therapy. However, prior fibrinolytic response to exercise dose not reduce the response to Complamin, nor is the fibrinolytic response to exercise reduced when exercise follows Complamin. It would therefore appear that resistance to repeated injections of Complamin is not due to exhaustion of the body's fibrinolytic potential. Side-effects of Complamin include flushing of the skin, abdominal pain, and hypotension, which may be severe. Because of the transient nature of the fibrinolytic response and the danger of hypotension, Complamin does not appear to have a place as a therapeutic agent in the treatment of thromboembolic occlusive vascular disease.

We are grateful to Professor E. M. McGirr for his interest in this work, and to the colleagues who volunteered to participate in the studies. Miss S. B. Gale provided scientific assistance and the Medical Research Council gave financial support. Complamin was made available by Dr. Jouhar, of Edinburgh Pharmaceutical Industries.

\section{REFERENCES}

Alkjaersig, N. (1960). In N.I.H. Conference on Thrombolytic Agents, edited by H. R. Roberts, and D. Geraty, p. 136. Chapel Hill. edited by H. R. Roberts, and D. Geraty, $\mathrm{p}_{\dot{j}}$ clin. Invest., 38, 1086. - Fletcher, A. P., and Sherry, S. (1959a). 7. clin.

Amery, A., Vermylen, J., Maes, H., and Verstraete, M. (1962). Nouv. Rev. franç. Hémat., 2, 70.

Biggs, R., and Macfarlane, R. G. (1962). Human Blood Coagulation and Its Disorders, 3rd ed., p. 372. Blackwell, Oxford.

Clement, W. E., and McNicol, G. P. (1959). F. clin. Path., 12, 544.

Douglas, A. S. (1962). Anticoagulant Therapy, p. 279. Blackwell, Oxford.

and McNicol, G. P. (1964). Brit. med. Bull., 20, 228.

Fletcher, A. P., Alkjaersig, N., and Sherry, S. (1959). F. clin. Invest., 38 1096.

Biederman, O., Moore, D., Alkjaersig, N., and Sherry S. (1964). Ibid., 43, 681.

Johnson, A. J., and McCarty, W. R. (1959). Ibid., 38, 1627.

von Kaulla, K. N. (1963). Chemistry of Thrombolysis: Human Fibrinolytic Enzymes, p. 244. Thomas, Springfield.

Kwaan, H. C., Lo, R., and MacFadzean, A. J. S. (1958). Clin. Sci., 17, 361.

McNicol, G. P., and Douglas, A. S. (1964). In Recent Advances in Clinical Pathology, series IV, edited by S. C. Dyke, p. 187. Churchill, London.

Gale, S. B., and Douglas, A. S. (1963). Brit. med. 7., 1, 909

Meneghini, P., and Piccinini, F. (1958). Arch. E. Maragliano Pat. Clin. 14, 69 .

Nilsson, I. M., and Olow, B. (1962). Acta chir. scand., 123, 247.

Ratnoff, O. D., and Menzie, C. (1951). F. Lab. clin. Med., 37, 316

Remmert, L. F., and Cohen, P. P. (1949). F. biol. Chem., 181, 431.

Sawyer, W. D., Fletcher, A. P., Alkjaersig, N., and Sherry, S. (1960). F. clin. Invest., 39, 426

Sherry, S., Fletcher, A. P., and Alkjaersig, N. (1959a). Physiol. Rev. 39, 343 .

Lindemeyer, R. Fletcher, A P and Alkjaersig, N. (1959b) \% clin. Invest., $38,810$.

Verstraete, M., Amery, A., and Vermylen, J. (1963). Brit. med. F., 1,

Weiner, M., de Crinis, K., Redisch, W., and Steele, J. M. (1959). Circulation, 19, 845 .

Redisch, W., and Steele, J. M. (1958). Proc. Soc. exp. Biol. (N.Y.), 98, 755 .

\title{
Effect of Obesity and of Starvation on Insulin Activity
}

\author{
N. SAMAAN, ${ }^{*} \ddagger$ M.B., B.CH., M.R.C.P.ED. ; J. BROWN, $\dagger$ M.B., B.S., B.SC., D.C.P. ; \\ RUSSELL FRASER,* M.D., F.R.C.P., D.P.M.; I. TRAYNER,* M.B., B.S.
}

Brit. med. F., 1965, 1, 1153-1156

It has long been established that obesity may lead to development of diabetes mellitus, and also that weight reduction often leads to a complete remission of this diabetes mellitus (Newburg and Conn, 1939). However, since diabetes in the obese, as well as other diabetic states, can be corrected by insulin, its basis may well be a relative insulin deficiency, whether from lack of production, excessive utilization, or both. Yet in obese diabetics measurement of the serum insulin-like activity usually shows normal or high levels, which at first sight does not seem to fit this hypothesis (Bornstein and Lawrence, 1951 ; Vallance-Owen et al., 1955 ; Seltzer and Smith, 1959; Steinke et al., 1961a, 1962 ; Samaan et al., 1962b). The present studies were therefore undertaken to try to clarify some of the factors affecting insulin activity in obesity.

In obese mice have been found hypertrophied pancreatic islet beta-cells, raised levels of serum insulin-like activity, both by bioassay and immunoassay, and also decreased tissue responsiveness to insulin; these features being found both in genetic obesity and in that induced by hypathalamic lesions (Christophe

* Department of Medicine, Postgraduate Medical School of London. † Department of Chemical Pathology, Postgraduate Medical School of London.

‡ Present address : Department of Medicine, Lakeside Hospital, Cleveland, Ohio, U.S.A et al., 1959 ; Hales and Kennedy, 1963 ; Sneyd, 1964). And, correspondingly, in obese humans there has also been found evidence both of hyperinsulinism and of insulin resistance ; for the former from serum insulin assays (Karam et al., 1963; Samaan and Fraser, 1963) and from forearm metabolic studies (Rabinowitz and Zierler, 1962), and for the latter from intravenous-insulin-tolerance tests, both by standard techniques (Fraser et al., 1962) and by localized forearm techniques (Rabinowitz and Zierler, 1962).

As Randle et al. (1963) have suggested, the diabetic tendency in obesity, as well as that in starvation and Cushing's syndrome, may arise from impairment of the action of insulin by the increased concentration of fat metabolites prevailing in these states. Certainly there are raised levels of serum free fatty acids in obesity (Gordon, 1960 ; Corvilain et al., 1961 ; Opie and Walfish, 1963), as well as in starvation where ketosis also prevails (Kekwick et al., 1959) ; and the action of insulin on tissue is known to be impaired either by raised free fatty acid levels (Williamson and Krebs, 1961; Shipp et al., 1961), or by increased concentrations of ketone bodies (Felts et al., 1964). But other factors must also be involved; since starvation, while indeed inducing in normal subjects a mild diabetes, can in the established diabetic considerably lessen his hyperglycaemia (Gephart et al., 1917 ; Allen, 1922). Presumably starvation 
also lowers the secretion and utilization of insulin to a basal range. Therefore, to study how obesity affected insulin activity and the serum insulin-like activity levels, observations were made both before and after a week's starvation on some diabetic and non-diabetic obese subjects. This paper compares the serum free fatty acid and insulin-like activity levels found at these two phases, first in a few rats and then during the glucose-tolerance tests on these human subjects.

\section{Plan of Study}

\section{Methods}

During the fast normal (220-220 g.) Worcester rats had access only to water ; at its conclusion in the morning they were bled under ether anaesthesia from the aorta, along with the litter mate controls in the same weight range. Each pair of sera pools so obtained was then included in the same assay run.

Two groups of obese patients were studied, one moderately obese (under $165 \%$ overweight) and one severely obese (over $155 \%$ overweight), each of these including both diabetic and non-diabetic subgroups. On the moderately obese only partial studies were made-that is, only measurements of serum insulin-like activity during a glucose-tolerance test under basal conditions after the standard diet preparation noted below. On the severely obese the main studies were made; each subject was first admitted to hospital, and given a diet containing 250-300 g. of carbohydrate daily for the three days prior to the first glucose-tolerance test. Then, after an overnight fast, a 50-g. oral glucose-tolerance test was performed, venous samples being taken fasting and at one and two hours, for the measurements noted below. Thereafter the subjects fasted for seven to nine days (taking only water, lemon tea, or coffee without milk or sugar ad lib.; throughout, their urines were checked and found to give positive $\mathrm{FeCl}_{3}$ tests for ketones); after which another $50-\mathrm{g}$. oral glucose-tolerance test was performed in the same manner.

\section{Patients Studied}

Eight severely obese subjects without other complicating disease were chosen for the main study; their weights ranged from 157 to $258 \%$ of the average for their height and age (Levine, 1923). Three of these, who were found to have diabetic glucose-tolerance tests (the two-hour blood sugars being $40 \mathrm{mg}$. or more over the fasting level), have been grouped separately as the subclinically diabetic obese group, and the remaining five form the non-diabetic obese group. For comparison, four of our new diabetic patients whose obesity was of the same degree $(162-200 \%)$ were chosen. The moderately obese were similarly chosen, the six non-diabetics being $145 \%$ (120-160\%) overweight and confirmed by glucose-tolerance test to be nondiabetic ; the nine diabetics were $155 \%$ (124-164\%) overweight, and their serum insulin-like activity values have already been published (Samaan and Fraser, 1963).

\section{Methods of Measurement}

The sera were kept in the deep-freeze until the time of assay. Blood sugar was measured on the Technicon AutoAnalyzer by the method of Hoffman (1937), which gives values $4 \mathrm{mg}$./ $100 \mathrm{ml}$. higher than true glucose, and whose standard error from duplicates is $\pm 3 \%$. Serum free fatty acids were estimated by colorimetric micro-determination as described by Duncombe (1964).

Insulin-like activity was measured with the epididymal fatpad of the rat in both the presence and the absence of insulin antiserum (Samaan et al., 1962a, 1962b). This bioassay procedure measures two types of insulin-like activity: the "typical" insulin-like activity, or that inhibited by antiserum, whose value is therefore obtained by difference, which is the form secreted by the pancreas, while the other or "atypical" insulin-like activity is not so inhibited by the antiserum. We have evidence that the atypical insulin-like activity is transformed by the liver from typical insulin-like activity, possibly by binding to some other substance, since it is a larger molecule, but it is not the same substance as the "bound insulin" of Antoniades et al. (1962) (Samaan et al., 1963). For the set of assays for each glucose-tolerance test a standard assay plan was used to minimize any influence from biological variation between rats (Samaan et al., 1962b).

\section{Results in Fasted Rats}

The fast has lowered both typical and atypical insulin-like activity to about one-third by the fourth day, and to unassayable levels by the seventh day (Fig. 1). The most obvious effect of the prolonged fast is on the atypical insulin-like activity levels, probably only because even in the normal controls the typical insulin-like activity levels are low at this time of day, nothing having been eaten for one to two hours.

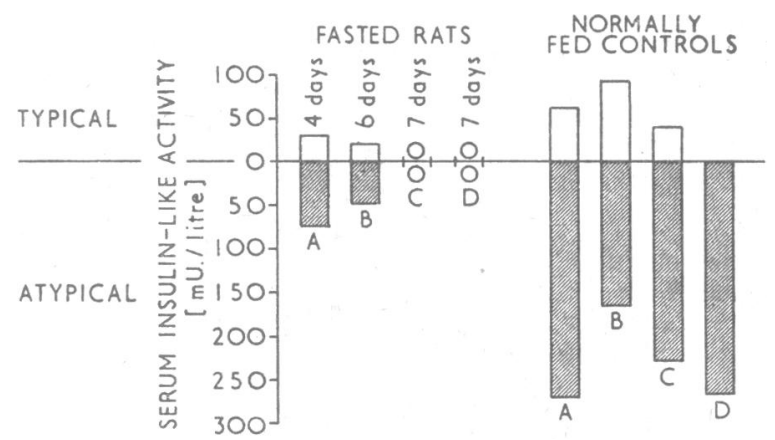

FIG. 1.-Morning serum insulin-like activity (typical and atypical) from rats fasted four, six, or seven days compared with that from normally fed controls. Note reduction on fasting finally to unmeasurable levels.

\section{Results in Severely Obese Patients Before and After a Week's Fast}

\section{Basal Status}

Glucose and Free Fatty Acid Levels (Fig. 2).-The free fatty acid levels are high in all groups; the mean initial or 0 -hour value of all 12 obese subjects being $329 \mu \mathrm{Eq} / 1$., or 115 above the mean normal value. ${ }^{1}$ After oral glucose these values drop in all groups by one hour to $53 \%$ of the initial value, and by two hours to $39 \%$ of the initial value-that is, at rather a subnormal rate (Hales and Randle, 1963 ; Randle et al., 1963). However, between these three small groups we have not discerned any characteristic difference. The blood-sugar curves which defined the group are also shown.

Scrum Insulin-like Activity.-Fig. 3 contrasts the three main severely obese groups with the two groups of moderately obese patients, and one group of normal subjects (Samaan and Fraser, 1963 ; Samaan, 1964). The atypical insulin-like activity level seems to rise with the degree of obesity, and the typical level is also correspondingly raised in the nondiabetic obese. Thus in the non-diabetic severely obese the levels of serum insulin-like activity, both typical and atypical, are clearly raised $(\mathrm{P}<0.001)$. However, as also found in other diabetics (Samaan and Fraser, 1963), in the overtly diabetic the typical insulin-like activity responses to glucose are delayed and very low. In the subclinical diabetic group this response in typical insulin-like activity is delayed, but possibly only less than that of the correspondingly obese non-diabetic group, although more measurements would be needed to determine

${ }^{1}$ Twelve normal subjects fasting showed $214 \pm \mu \mathrm{Eq} / 1$. of serum. 
this last point. Only in the non-diabetic obese does the serum typical insulin-like activity rise and fall sharply after oral glucose-that is, with a normal speed and percentage rise. Thus, apart from the inadequate and delayed rise in serum typical insulin-like activity associated with diabetes when present, in obesity approximately equivalent rises in the level of serum typical and atypical insulin-like activity occur, and to an extent apparently dependent on the degree of obesity. and two hours after the glucose ; the levels being approximately double the pre-fast values, but falling after the glucose at the same percentage rate as before the fast (see semi-log plot on Fig. 4).

Serum Insulin-like Activity.- (a) Atypical : Evidently corresponding with these changes in serum free fatty acid, the levels of atypical insulin-like activity have also about doubled after the fast, the change being approximately equivalent in all groups. (b) Typical: The levels of typical insulin-like activity have also about doubled, but the response curves after glucose are altered, and the diabetic obese are now less different from the other groups. All three groups now show the pattern of response seen previously only with subclinical diabetes -a good one-hour rise which has subsided but little by the second hour. While this response to glucose is still greatest in the nondiabetic obese, the response of the diabetic obese, comprising a rise of $+200 \%$ by the first hour, now approximates to that of the others, and so has been restored towards that seen in the non-diabetic obese.

Correlation Between Percentage Changes in Free Fatty Acid and Insulin-like Activity Levels after the Fast.-Although the numbers studied are really too small, the percentage rise after the fast in serum atypical insulin-like activity tends to correspond with that in basal or 0-hour serum free fatty acid (see Fig. 5). Perhaps the diabetic group may also have a somewhat greater

FIG. 2.- Serum glucose and free fatty acid levels during glucose-tolerance test in severe obesity \pm diabetes before and after seven days' fast (mean \pm S.E.). Note, after fast, lowered fasting blood sugars and mild starvation diabetic glucose-tolerance tests in all groups, that of diabetic group being now less abnormal and like that of non-diabetic group. Free fatty acid levels are high in all groups basally and more so after fast; and their fall during glucose-tolerance test occurs before and after the fast.

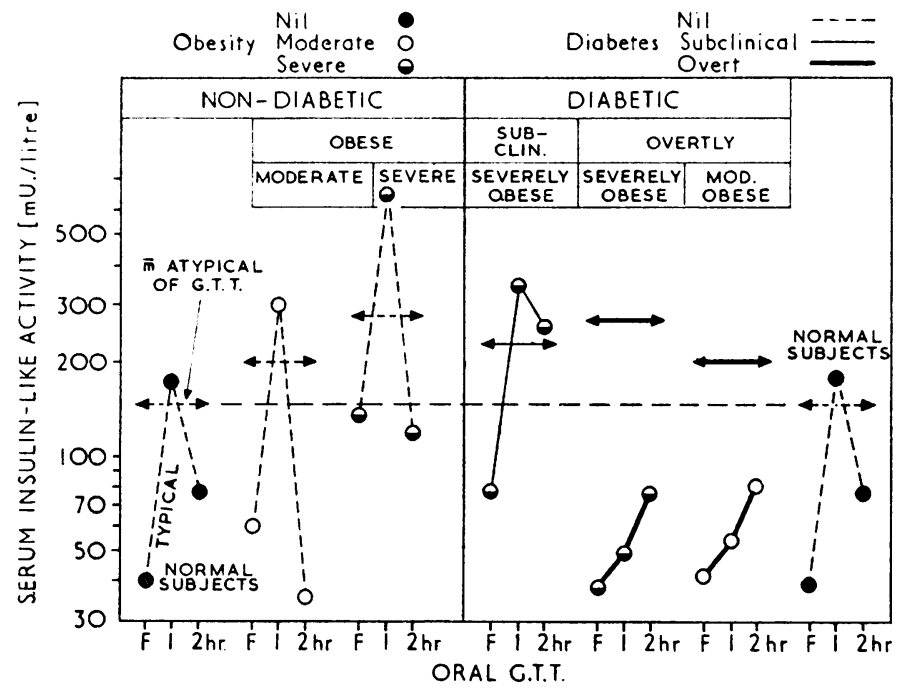

FIG. 3.-Serum insulin-like activity (typical and atypical) during glucosetolerance test; in moderate or severe obesity with and without diabetes. Note rising levels of both types of insulin-like activity with increasing obesity, while concurrent diabetes causes lowering only of levels of typical insulin-like activity.

\section{Effect of Seven Days' Complete Fast}

Blood Sugar (Fig. 2).-The fasting blood sugar has fallen in all groups, into the normal range for the diabetic obese, and down into the low normal range for the other two obese groups. On the other hand, the glucose-tolerance test of the diabetic obese is now no more diabetic than before the fast, the two-hour values still showing the same mean increment over the fasting level ; while the other two groups now both show "starvation diabetes "- that is, their mean two-hour values are now similarly raised to 67 and $110 \mathrm{mg} . / 100 \mathrm{ml}$. respectively above the fasting levels.

Serum Free Fatty Acid (Fig. 1).-After the fast the free fatty acid levels are strikingly higher both basally and at one rise in serum insulin-like activity than do the other obese subjects.

\section{Discussion}

Despite this being a preliminary study of small groups, the level of the serum insulin-like activity found in the nondiabetic but grossly obese patients is shown to be high, both typical and atypical insulin-like activity being three to four times normal. There is also a hint that the degree of obesity determines the extent of this rise. Further studies might define the rise in serum insulin-like activity to be expected from the duration and extent of the obesity in non-diabetic subject. For the moment, these findings merely emphasize the difficulties

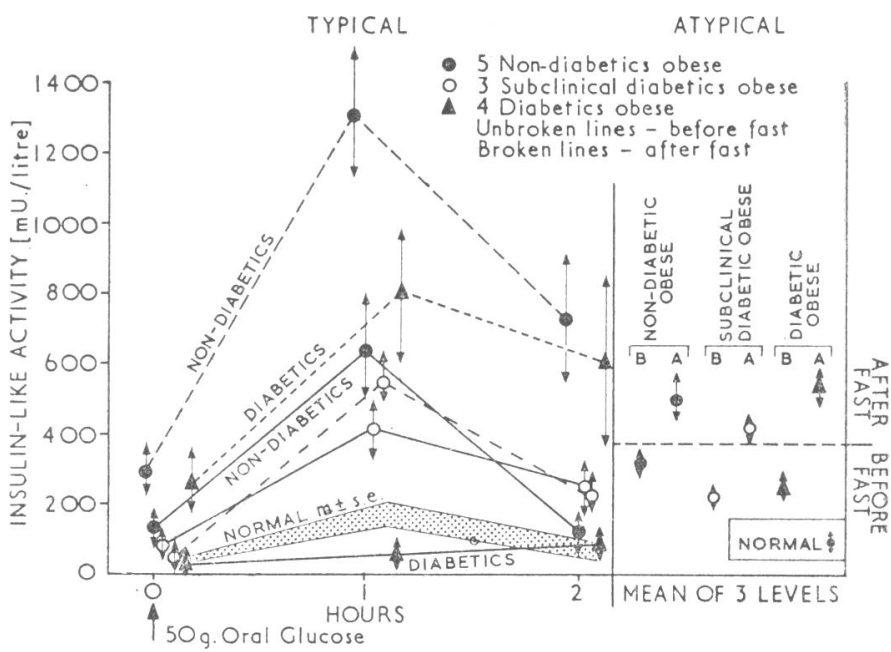

FIG. 4.-Serum insulin-like activity during glucose-tolerance test before and seven days' fast in severe obesity \pm diabetes (mean \pm S.E.). Note in all groups high atypical insulin-like activity levels before fast, which rise further after fast. Typical insulin-like activity levels also rise after fast in all groups, reaching highest levels in non-diabetic group; these were also abnormally high basally in all groups except the overtly diabetic whose levels were subnormal before the fast. 
involved in assessing whether a subject's serum insulin-like activity is abnormal, without also assessing the extent and duration of his obesity, and knowing how to allow for these. Several recent studies drawing attention to the raised levels of serum insulin-like activity in early diabetes, or in pre-diabetic subjects (Seltzer et al., 1956 ; Yalow and Berson, 1960 ; Steinke et al., $1961 \mathrm{~b})$, therefore need reappraisal in relation to the subjects' obesity. Our experiments have not assessed the cause of these high insulin levels in obesity, but they probably do develop to overcome the impeding effects of high free fatty acid levels on the action of insulin, as suggested by Randle et al. (1963).

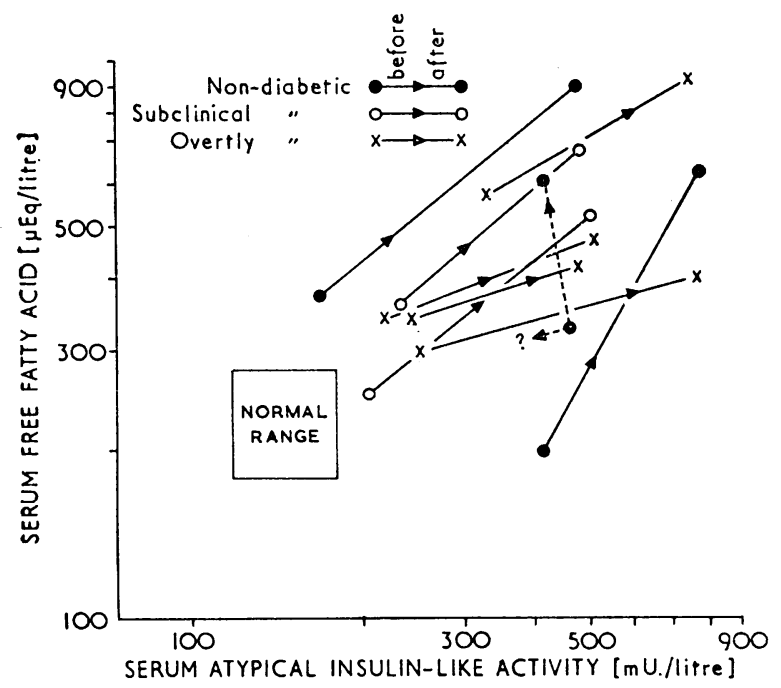

FIG. 5.-Serum free fatty acid and atypical insulin-like activity in severe obesity before and after seven days' fast (10 severely obese t diabetes). Note tendency to correspondence in rises (the obvious exception had an unusually high free fatty acid level before the fast-possibly an error of estimation).

Our previous studies of serum insulin-like activity in the main types of diabetes mellitus have already set aside the diabetic obese as unusual in having high serum atypical insulin-like activity, while, like all other diabetic groups, they show a defective typical insulin-like activity response to oral glucose (Samaan and Fraser, 1963). The present studies have revealed a high serum atypical insulin-like activity as a feature of obesity with or without diabetes. It is perhaps surprising that the atypical insulin-like activity levels have not fallen with the onset of diabetes. Possibly the steady basal insulin production determines this level, and in mild diabetes the main defect may be a lack of reserve insulin-secretory capacity which is revealed only after oral glucose.

In the non-diabetic obese subjects the effects observed to follow the starvation were perhaps not unexpected-not only a rise of all types of serum insulin-like activity in the face of fat mobilization and ketosis, but also a slowing of the typical insulin-like activity response to glucose. However, in the diabetic group there was a greater rise in serum insulin-like activity, especially of typical insulin-like activity and a lesser rise in free fatty acids. The fast, perhaps by lessening the utilization of insulin, may have rested the pancreas and enabled some recovery of insulin-secretory reserve in this diabetic group; although the reason for the lesser rise in free fatty acids is not too clear.

The different response to the fast seen in the rat is puzzling. It underlines decreased production and utilization of insulin as phenomena of the fast, which the recovery just noted in the obese diabetic patients has also suggested. During the fast, changes in other hormonal productions are known to occurfor example, increased cortisol and growth-hormone production (Cohen, 1958 ; Eckert et al., 1961 ; Slater et al., 1962 ; Roth et al., 1963). Possibly the hormonal balance of the rat is so different from that of man that the fall in insulin utilization is more extensive than the associated increase in insulin resist- ance; for it is probably the latter which leads to the rise in serum insulin-like activity on fasting.

\section{Summary}

The effect of a seven-day fast on the serum levels of insulinlike activity, of free fatty acids, and of glucose during a glucosetolerance test was studied in three groups of severely obese subjects ; $(a)$ five non-diabetic, (b) three subclinically diabetic, and $(c)$ four diabetic.

Before the fast the non-diabetic obese subjects showed higher levels of both types of serum insulin-like activity than were found in normal subjects, while the diabetic obese subjects showed similarly raised "atypical" insulin-like activity levels, but like other diabetics low "typical" insulin-like activity levels.

After a seven-day fast the insulin-like activity levels and the glucose-tolerance curves of diabetic obese subjects became more like those of the other obese subjects; while all obese groups then showed diabetic glucose-tolerance curves, lower fasting serum glucose, higher serum insulin-like activity levels, and higher free fatty acid levels. The percentage rise in free fatty acid after the fast tended to correspond with that in atypical insulin-like activity. Evidently fasting lessens the demand for insulin, despite its causing insulin resistance, possibly from increased fat mobilization.

\section{REFERENCES}

Allen, F. M. (1922). 7. metab. Res., 1, 5

Antoniades, H. N., Bougas, J. A., and Pyle, H. M. (1962). New Engl. f. Med., 267, 218.

Bornstein, J., and Lawrence, R. D. (1951). Brit. med. f., 2, 1541.

Cohen, H. (1958). Ibid., 1, 686 .

Corvilain, J., Loeb, H., Champenois, A., and Abramow, M. (1961). Lancet, 1, 534 .

Christophe, J., Dagenais, Y., and Mayer, J. (1959). Nature (Lond.), 184,61 .

Duncombe, W. G. (1964). Clin. chim. Acta, 9, 122.

Eckert, J. P., Green, D. C., and Migean, C. J. (1961). 43rd Annual Meeting of the Endocrine Society, June 1961. Abstract No. 76, p. 41

Felts, P. W., Crofford, O. B., and Park, C. R. (1964). ₹. clin. Invest., 43, 638.

Fraser, R., Joplin, G. F., Opie, L. H., and Rabinowitz, D. (1962). $\mathcal{F}$ Endocr., 25, 299.

Gephart, F. C., Aub, J. C., Du Bois, E. F., and Lusk, G. (1917). Arch. intern. Med., 19, 908.

Gordon, E. S. (1960). Amer. 7. clin. Nutr., 8, 740.

Hales, C. N., and Kennedy, G. C. (1963). British Diabetic Association Medical Scientific Meeting, 11 October 1963. and Randle, P. J. (1963). Lancet, 1, 790.

Hoffman, W. S. (1937). f. biol. Chem., 120, 51.

Karam, J. H., Grodsky, G. M., and Forsham, P. H. (1963). Diabetes, 12, 197.

Kekwick, A., Pawan, G. L. S., and Chalmers, T. M. (1959). Lancet,

Levine, A. (1923). F. Inst. Actu., 54, 216.

Newburgh, L. H., and Conn, J. W. (1939). F. Amer. med. Ass., 112,

Opie, L. H., and Walfish, P. G. (1963). New Engl. f. Med., $268,757$.

Opie, L. H., and Walfish, P. G. 1963). New Engl. f. Med., 268, 757.

Randle, P. J., Garland, P. B., Hales, C. N., and Newsholme, E. A. (1963). Lancet, 1, 785 .

Roth, J., Glick, S. M., Yalow, R. S., and Berson, S. A. (1963). Science, 140, 987.

Samaan, N. (1964). The biological effects of insulin on the fat pad with and without antibody, and the indications of two types of insulin in in blood. Thesis presented for Ph.D. Degree, University of London. (1962a). F. Endocr., 24, 263.

(1962a). F. Endocr., 24, 263. (1962b). Ibid., 2, 1287

Stillman, D., and Fraser, R. (1962b).

- and Fraser, R. (1963). Ibid., 2, 311.

Seltzer, H. S. Fajans, S. S., and Conn, J. W. (1956). Diabetes, 5, 437. Seltzer, H. S., Fajans, S. S., and I I Lid., 8, 417 .

Shipp, J. C., Opie, L. H., and Challoner, D. (1961). Nature (Lond.), $189,1018$.

Slater, J. D. H., Hartog, M., Fraser, R., and Rantzen, B. (1962). Brit. med. F., 1, 1584.

Sneyd, J. G. T. (1964). F. Endocr., 28, 163. Metabolism, 1.0, 707. Metabolism, 1.0, 707. Renold, A. E. (1961b). Lancet, 1, 30

- Taylor, K. W., and Renold, A. E. (1961b). Lancet, 1, 30. - Soeld

Vallance-Owen, J., Hurlock, B.. Pl.ase, N. W. (1955). Lancet, 2, 583.

Williamson, J. R., and Krebs, Y.. A. (1961). Biochem. F., 80, 540.

Yalow, R. S., and Berson, S. A. (1960). Diabetes, 9, 254. 